\title{
BMJ open Trends in social inequalities for premature coronary heart disease mortality in Great Britain, 1994-2008: a time trend ecological study
}

\author{
David McCartney, ${ }^{1,2}$ Peter Scarborough, ${ }^{1}$ Premila Webster, ${ }^{1}$ Mike Rayner ${ }^{1}$
}

To cite: McCartney D, Scarborough $\mathrm{P}$, Webster $\mathrm{P}$, et al. Trends in social inequalities for premature coronary heart disease mortality in Great Britain, 1994-2008: a time trend ecological study. BMJ Open 2012;2:e000737.

doi:10.1136/

bmjopen-2011-000737

- Prepublication history for this paper is available online. To view these files please visit the journal online (http:// dx.doi.10.1136/ bmjopen-2011-000737).

Received 6 December 2011 Accepted 3 May 2012

This final article is available for use under the terms of the Creative Commons Attribution Non-Commercial 2.0 Licence; see http://bmjopen.bmj.com

${ }^{1}$ Department of Public Health, University of Oxford, Oxford, UK

${ }^{2}$ Department of Primary Care Health Sciences, University of Oxford, Oxford, UK

Correspondence to Dr David McCartney; david. mccartney@seh.ox.ac.uk

\section{ABSTRACT \\ Objective: To compare trends in metrics of socioeconomic inequalities in premature coronary heart disease (CHD) mortality in Great Britain. \\ Design: Time trend ecological study with area-level deprivation as exposure.}

Setting: Great Britain, 1994-2008.

Participants: Men and women aged younger than 75 years. No lower age limit.

Interventions: None.

Main outcome measures: CHD mortality rates.

Results: There has been a decrease in socioeconomic inequalities in CHD mortality in absolute terms but an increase in relative terms. CHD mortality rates in men aged younger than 75 years fell by 69 per 100000 (95\% Cls 64 to 74 ) in the least deprived quintile and by 92 per 100000 (95\% Cl 86 to 98$)$ in the most deprived quintile ( $p$ for trend: $<0.001$ ). Mortality rate ratios comparing the most deprived quintile to the least deprived quintile increased in women aged younger than 75 years from $1.77(95 \% \mathrm{Cl} 1.68$ to 1.86$)$ to 2.32 $(95 \% \mathrm{Cl} 2.14$ to 2.52$)$. There was a weak negative association between the average decline of relative rates and area deprivation.

Conclusions: It could either be said that inequalities in premature mortality from CHD between affluent and deprived areas have widened or narrowed between 1994 and 2008 depending on the measurement technique. In the context of falling CHD mortality rates, narrowing of absolute inequalities is to be expected, but increases in relative inequalities are a cause for concern.

\section{INTRODUCTION}

There have been widespread social inequalities in health for many years, with higher mortality rates in more deprived areas than those that are less deprived. ${ }^{1}$ The Independent Inquiry into Inequalities in Health in the late 1990s documented a widening of inequalities in mortality ${ }^{2}$ and most recently the publication 'Fair Society, Healthy Lives' reported the persistence of inequalities across a range of health outcomes. ${ }^{3}$ Coronary

\section{ARTICLE SUMMARY}

Article focus

- CHD mortality in Great Britain has declined steadily over the past 30 years.

- Socioeconomic inequalities in CHD mortality have persisted for many years.

- There are different assessments as to whether inequalities in CHD are widening or narrowing, depending on whether absolute or relative measurements are considered.

Key messages

- There has been a narrowing in Great Britain of absolute socioeconomic inequalities in premature CHD mortality rates over the past 15 years.

- There has been a substantial widening in relative socioeconomic inequalities over this time period, particularly for women.

- Although relative decline in premature CHD mortality rates over this time period is clearly socially patterned, area-level deprivation only explains a small amount of the variance in rates of decline.

Strengths and limitations of this study

- The strengths of this study are that trends are examined across the whole of Great Britain over a significant period of time.

- However, deprivation was only assessed at a single point in time and therefore this may have resulted in misclassification over time.

- CHD is a condition with a long aetiology; therefore, area of residence at death is a limited indicator of socioeconomic status over the life course.

heart disease (CHD) outcomes are a good indicator of social inequalities in health since many of the behavioural and medical risk factors for CHD are socially patterned. ${ }^{4}$ It is the cause for around one in 10 deaths in women aged younger than 75 years and one in five deaths in men aged younger than 75 years, ${ }^{4}$ and there is wide variation in CHD mortality across different socioeconomic groups, with rates for men living in the most 
deprived twentieth in England and Wales in 2004 more than three and a half times higher than rates in the least deprived twentieth. ${ }^{5}$ Reduction in social inequalities in CHD mortality was a key health target for the recent labour government. ${ }^{6}$

Trends in overall CHD mortality rates have been declining in Great Britain since the 1970s. In the last 10 years, premature (younger than 75 years) mortality rates have fallen by around $45 \%{ }^{4}$ This reflects both improvements in cardiovascular risk factor profiles (primarily reductions in smoking) and advancements in treatment. ${ }^{7-9}$ However, improvements in prevention or treatment can occur at different rates for different socioeconomic groups, ${ }^{10}$ which could result in widening of inequality.

Evidence on socioeconomic trends in CHD mortality is difficult to interpret because of differences in methodology and inconsistencies in definitions of areas and populations. Trends can be expressed in absolute terms or relative terms ${ }^{11}$ and provide different assessments of whether social inequalities in health are currently widening or narrowing. While some studies have suggested that inequalities in mortality have not only persisted but may have increased in England and in other European countries, ${ }^{12-14}$ other analyses have reported a narrowing of inequalities. ${ }^{6}{ }^{15}$ It has been argued that both absolute and relative trends should be presented ${ }^{16}$ because as Blakely et al ${ }^{17}$ highlighted, relative differences can often increase in the context of decreasing absolute differences.

This study undertakes a comprehensive analysis of trends in CHD mortality over a 15-year period between 1994 and 2008 in Great Britain reporting inequalities in both absolute and relative terms.

\section{METHODS}

Annual CHD mortality rates were constructed for each unitary authority and local authority district in Great
Britain ( $\mathrm{n}=408$, henceforth 'local authority') for the years 1994-2008 inclusive. The time period coincides with the provision of statistics using consistent local authority boundaries, allowing for analysis using small areas over a 15-year period. Deaths in Great Britain with CHD listed as the primary cause of death (ICD-9 410-414; ICD-10 I20-25) were included. Mortality rates were constructed for premature mortality (under the age of 75) for men and women separately. Death certificate data were obtained for England and Wales from the Office for National Statistics and for Scotland from the Government Registry Office for Scotland. Data were obtained by sex, 5-year age group and local authority of residence. Population data were taken from local authority estimates extrapolated from the 1991 and 2001 censuses constructed by the Office for National Statistics and Government Registry Office for Scotland. Mortality rates were adjusted for age by using the direct method of standardisation, using the European Standard Population as the reference population.

The Carstairs index for 2001 was used as the area-level measure of deprivation. ${ }^{18}$ The index is a standardised sum of the proportion of all unemployed men, persons in households with one or more persons per room, proportion of residents in households with no car and proportion of residents in households with head of household in Social Class IV or V (Registrar General's classification).$^{19}$ For this study, we calculated the index for all local authorities in Great Britain using census data available from 2001 based on methodology available from the University of Manchester. ${ }^{20}$ Areas were then grouped into quintiles according to their Carstairs score, and the mean mortality rates were calculated for each quintile. The Carstairs index has previously been shown to be strongly correlated with male and female CHD rates for local authorities in England and Wales. ${ }^{5}$

This study uses several different approaches to assess trends in socioeconomic inequalities in CHD mortality.
Figure 1 Age-standardised coronary heart disease mortality rates per 100000 for the period 1994 to 2008, by quintile of deprivation, Great Britain-women younger than 75 years.

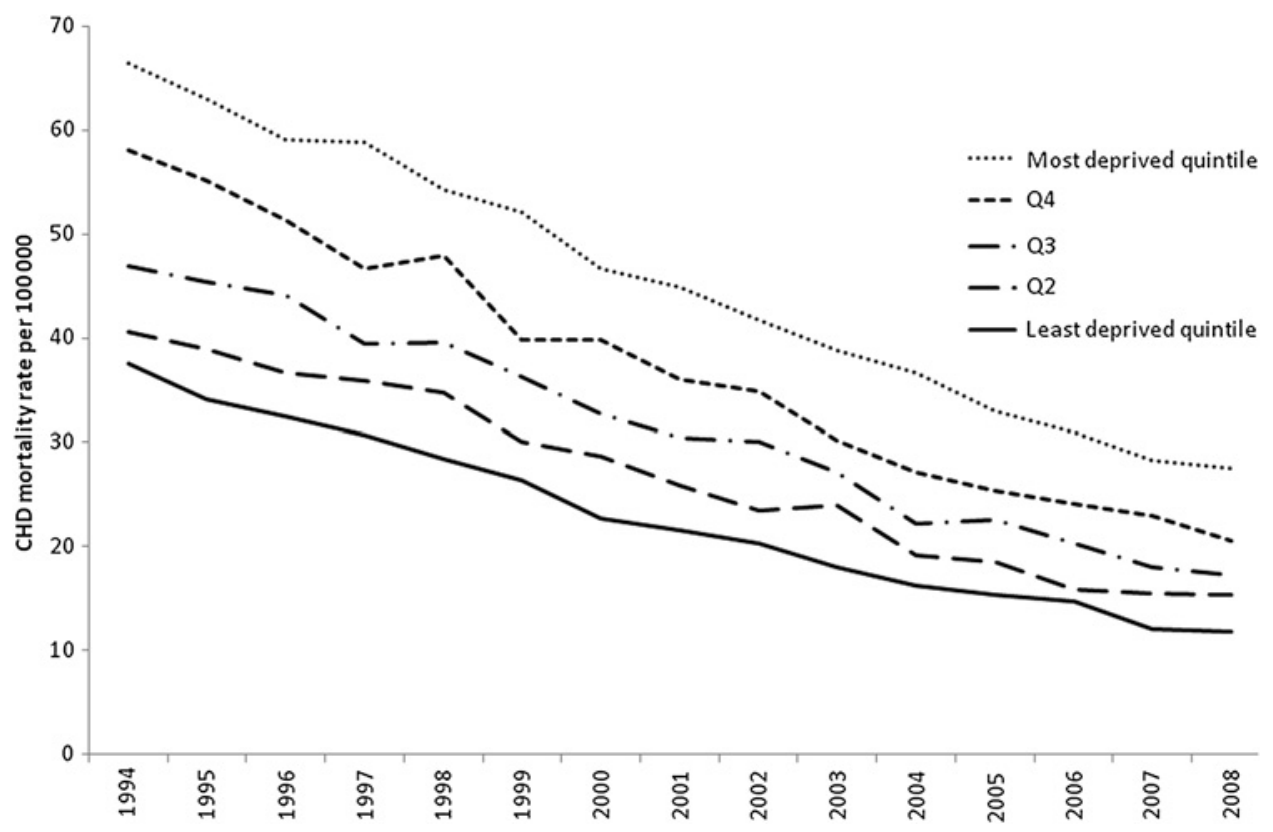


First, trends in mean absolute CHD mortality rates across different quintiles were calculated. Second, the same trends were calculated in relative terms. For every quintile, the mean absolute mortality for each year was calculated as a percentage of the mean absolute mortality rate in the first year of analysis (1994) to demonstrate the percentage change in rates since the baseline year. Non-parametric tests for trend developed by Cuzick were conducted to assess significance of trends in relative and absolute decline in mortality rates by quintile of deprivation. Third, mortality rate ratios were calculated for each year, with mortality rates in the least deprived quintile used as the base of the ratio. Finally, the association between mean annual percentage decline in mortality rates and area-level deprivation for local authorities was assessed. The annual average percentage decline over the 15 -year period was calculated independently for each local authority. This was done using a linear regression analysis of relative mortality rates over the 15 -year period in each local authority to generate a $\beta$ coefficient value that was used as a marker of average annual percentage decline. The relationship between this $\beta$ coefficient value and the associated Carstairs Deprivation index for each individual local authority was then assessed using a second linear regression analysis. The $95 \%$ CIs were calculated for changes in absolute and relative mortality rates by quintile and for rate ratios between the most and least deprived quintile in each year. All analyses were performed using Stata version 10.

\section{RESULTS}

\section{Absolute decline}

Mortality rates for CHD declined steadily between 1994 and 2008 for areas at all levels of deprivation. Figure 1 shows the decline in CHD mortality rates for women

Table 1 Comparison of deprivation quintiles of local authorities in the assessment of (a) change in absolute coronary heart disease (CHD) mortality rates, (b) change in relative CHD mortality rates, (c) change in CHD mortality rate ratio between least and most deprived quintiles and (d) association between average annual percentage decline and deprivation, 1994-2008, Great Britain, $\mathrm{n}=408$

\begin{tabular}{|c|c|c|c|c|c|c|c|c|}
\hline \multicolumn{9}{|c|}{ (a) Absolute change in CHD mortality rates per 100000} \\
\hline & \multicolumn{4}{|l|}{ Men } & \multicolumn{4}{|l|}{ Women } \\
\hline & 1994 & 2008 & Change & $95 \% \mathrm{Cls}$ & 1994 & 2008 & Change & $95 \% \mathrm{Cls}$ \\
\hline Q1 & 113 & 44 & -69 & -74 to -64 & 37 & 12 & -26 & -28 to -23 \\
\hline Q2 & 124 & 48 & -77 & -80 to -73 & 41 & 15 & -25 & -28 to -23 \\
\hline Q3 & 137 & 57 & -80 & -85 to -75 & 47 & 17 & -30 & -33 to -26 \\
\hline Q4 & 156 & 68 & -89 & -94 to -84 & 58 & 20 & -37 & -40 to -34 \\
\hline Q5 & 172 & 81 & -92 & -98 to -86 & 66 & 28 & -39 & -42 to -36 \\
\hline \multirow{2}{*}{\multicolumn{3}{|c|}{$\begin{array}{l}\text { p For trend } \\
\text { (b) Relative change in CHD mortality rates }\end{array}$}} & \multicolumn{2}{|c|}{$<0.001$} & \multicolumn{2}{|c|}{$\mathrm{p}$ For trend } & \multicolumn{2}{|c|}{$<0.001$} \\
\hline & & & & & \multirow{2}{*}{\multicolumn{4}{|c|}{ Women }} \\
\hline & \multicolumn{4}{|c|}{ Men } & & & & \\
\hline & \multicolumn{2}{|c|}{$\begin{array}{l}\% \text { Change } \\
1994-2008\end{array}$} & \multicolumn{2}{|l|}{$95 \% \mathrm{Cls}$} & \multicolumn{2}{|c|}{ \% Change 1994-2008 } & \multicolumn{2}{|l|}{$95 \% \mathrm{Cls}$} \\
\hline Q1 & \multicolumn{2}{|c|}{-60} & \multicolumn{2}{|c|}{-62 to -58} & \multicolumn{2}{|l|}{-66} & \multicolumn{2}{|c|}{-69 to -62} \\
\hline Q2 & \multicolumn{2}{|l|}{-61} & \multicolumn{2}{|c|}{-63 to -59} & & \multicolumn{2}{|c|}{-64 to -57} \\
\hline Q3 & \multicolumn{2}{|l|}{-58} & \multicolumn{2}{|c|}{-59 to -56} & \multicolumn{2}{|l|}{-61} & \multicolumn{2}{|c|}{-64 to -57} \\
\hline Q4 & \multicolumn{2}{|l|}{-56} & \multicolumn{2}{|c|}{-58 to -54} & \multicolumn{2}{|l|}{-63} & \multicolumn{2}{|c|}{-66 to -60} \\
\hline & \multirow{2}{*}{\multicolumn{2}{|c|}{-53}} & \multicolumn{2}{|c|}{-55 to -50} & \multirow{2}{*}{\multicolumn{2}{|c|}{$\begin{array}{l}-57 \\
\mathrm{p} \text { For trend }\end{array}$}} & \multirow{2}{*}{\multicolumn{2}{|c|}{$\begin{array}{l}-60 \text { to }-54 \\
0.001\end{array}$}} \\
\hline $\mathrm{p}$ For trend & & & $<0.001$ & & & & & \\
\hline & Men & & & & Women & & & \\
\hline & 1994 & $95 \% \mathrm{Cls}$ & 2008 & $95 \% \mathrm{Cls}$ & 1994 & $95 \% \mathrm{Cls}$ & 2008 & $95 \% \mathrm{Cls}$ \\
\hline Q2 & 1.10 & 1.06 to 1.14 & 1.09 & 1.03 to 1.15 & 1.08 & 1.02 to 1.15 & 1.29 & 1.17 to 1.42 \\
\hline Q3 & 1.21 & 1.17 to 1.25 & 1.30 & 1.23 to 1.37 & 1.25 & 1.18 to 1.32 & 1.46 & 1.33 to 1.60 \\
\hline Q4 & 1.38 & 1.34 to 1.43 & 1.54 & 1.47 to 1.62 & 1.55 & 1.47 to 1.63 & 1.74 & 1.60 to 1.90 \\
\hline Q5 & 1.52 & 1.47 to 1.57 & 1.84 & 1.76 to 1.93 & 1.77 & 1.68 to 1.86 & 2.32 & 2.14 to 2.52 \\
\hline
\end{tabular}

(d) Average annual percentage decline in CHD mortality rates

\begin{tabular}{|c|c|c|c|c|}
\hline \multicolumn{3}{|c|}{ Men } & \multicolumn{2}{|l|}{ Women } \\
\hline & Range & IQR & Range & IQR \\
\hline Q1 & -5.6 to -2.2 & -4.7 to -3.9 & -7.7 to -0.6 & -5.3 to -4.0 \\
\hline Q2 & -6.6 to -2.9 & -4.9 to -4.0 & -8.1 to -2.2 & -5.5 to -4.2 \\
\hline Q3 & -6.5 to -3.1 & -4.7 to -4.0 & -7.5 to -2.7 & -5.1 to -4.1 \\
\hline Q4 & -6.5 to -2.9 & -4.7 to -4.0 & -8.9 to -2.6 & -5.3 to -4.0 \\
\hline Q5 & -6.8 to -2.9 & -4.6 to -3.9 & -11.0 to -2.1 & -5.4 to -4.1 \\
\hline $\begin{array}{l}r^{2} \text { For explanation of average } \\
\text { annual decline by deprivation: }\end{array}$ & & 0.06 & & 0.04 \\
\hline p For regression line & & $<0.001$ & $p$ For regression line & $<0.001$ \\
\hline
\end{tabular}


younger than 75 years since 1994, by quintile of deprivation. Mortality rates in the more deprived groups have seen a greater absolute fall than more affluent areas. This has resulted in a narrowing of inequalities in absolute mortality rates over the time period. This pattern was the same for men younger than 75 years. Table 1 shows that the most deprived quintile had a significantly greater decline in CHD mortality rates than the least deprived quintile, for both men and women. For men, mortality rates fell by 69 (95\% CI 64 to 74) per 100000 in the most affluent quintile compared with $92(95 \%$ CI 86 to 98$)$ per 100000 in the least affluent quintile.

\section{Relative decline}

Figure 2 shows the relative decline in CHD mortality rates for men younger than 75 years by quintile of deprivation. The relative decline in the most deprived quintile between 1994 and 2008 was less than the relative decline in the least deprived quintile, and there was a clear gradient in decline within deprivation quintiles. At no point between 1994 and 2008 was the relative decline in the most deprived quintile greater than that in the least deprived quintile. For women, mortality rates in the most affluent quintile declined by $66 \%$ (62\% to $69 \%$ ) compared with $57 \%$ (95\% CI $54 \%$ to $60 \%$ ) for the least affluent quintile (see table 1).

\section{Mortality rate ratios}

Mortality rate ratios were calculated using the least deprived quintile as the base. The rate ratios by quintiles of deprivation are shown for women younger than 75 years in figure 3 . For both men and women, the rate ratio for the most deprived quintile increased reasonably consistently between 1994 and 2008. In men younger than 75 years, the increased risk in the most deprived group changed from 52\% (95\% CI 47\% to 57\%) in 1994 to $84 \%$ (95\% CI $76 \%$ to $93 \%$ ) in 2008. For women younger than 75 years, the increased risk in the most deprived quintile changed from $77 \%$ (95\% CI $68 \%$ to $86 \%$ ) in 1994 to $132 \%$ (95\% CI $114 \%$ to $152 \%$ ) in 2008.

\section{Association between average annual percentage decline and deprivation}

Figure 4 shows the association between average annual decline in men younger than 75 years CHD mortality rates and deprivation for all local authorities in Great Britain. The variables demonstrate a weak association $\left(\mathrm{r}^{2}=0.06, \mathrm{p}<0.001\right)$. The association suggests that more deprived areas have a slower rate of decline in relative CHD mortality rates than more affluent areas. However, the weak association suggests that the level of deprivation of the local authority alone does little to describe the variance in decline in CHD mortality rates. This is the case for both men and women younger than 75 years CHD mortality rates and is demonstrated in table 1 , where the IQR of average annual decline in CHD mortality rates for local authorities in the most and least deprived quintiles overlap considerably.

\section{DISCUSSION}

This study investigated the trends in premature CHD in relation to socioeconomic inequalities in Great Britain over a 15-year period. The findings show that while absolute inequalities in mortality have narrowed, there has been a clear widening of relative inequalities. A stark consequence is that female premature CHD mortality rates in the most deprived quintile are now more than double those in the least deprived quintile, and this gap is still increasing. The social patterning displayed in these trends is evident across the whole spectrum of deprivation, with the relative gap between any two quintiles of deprivation increasing over the time period 1994-2008 (see figure 3). However, when trends in the individual local authorities are assessed, it is clear that
Figure 2 Relative coronary heart disease mortality rates $(1994=100 \%)$ for the period 1994 to 2008 , by quintile of deprivation, Great Britain-men younger than 75 years.

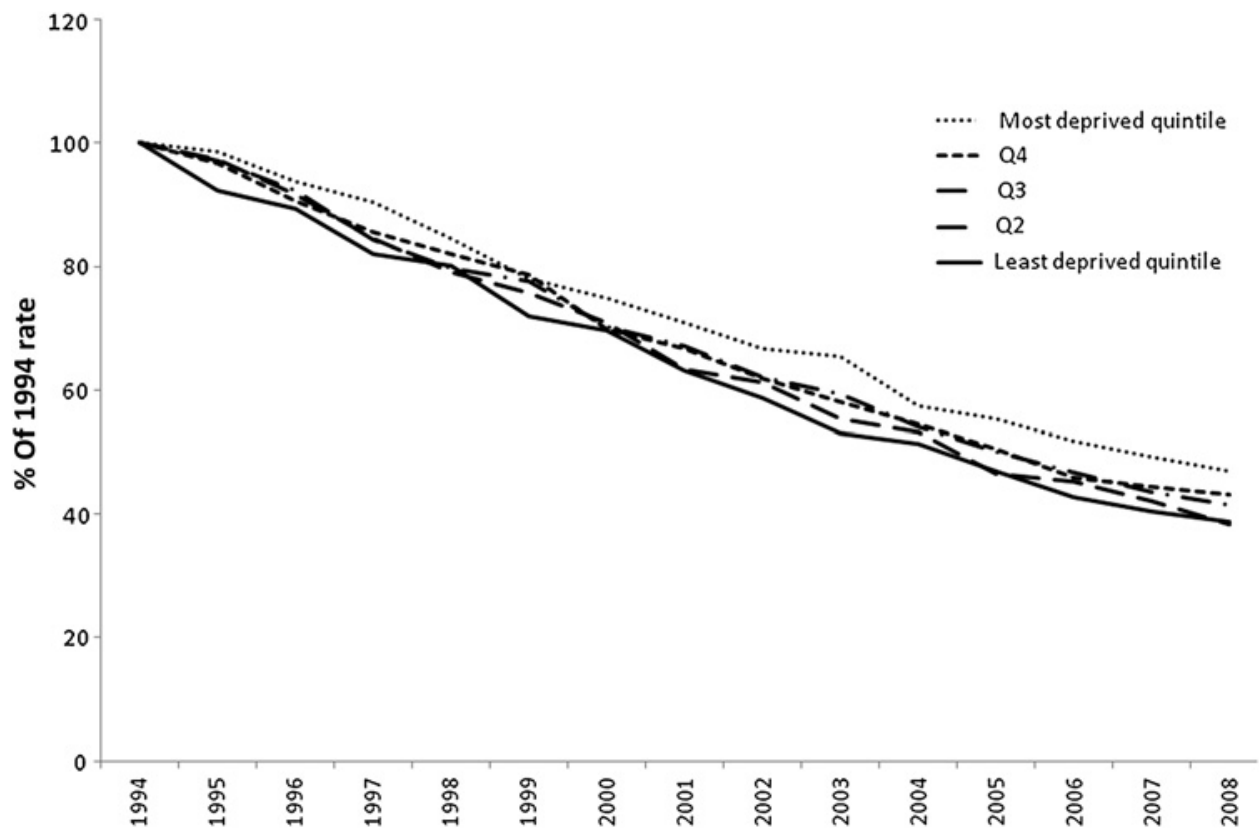


Figure 3 Coronary heart disease mortality rate ratios (least deprived quintile as baseline) for the period 1994 to 2008 by quintile of deprivation, Great Britain-women younger than 75 years.

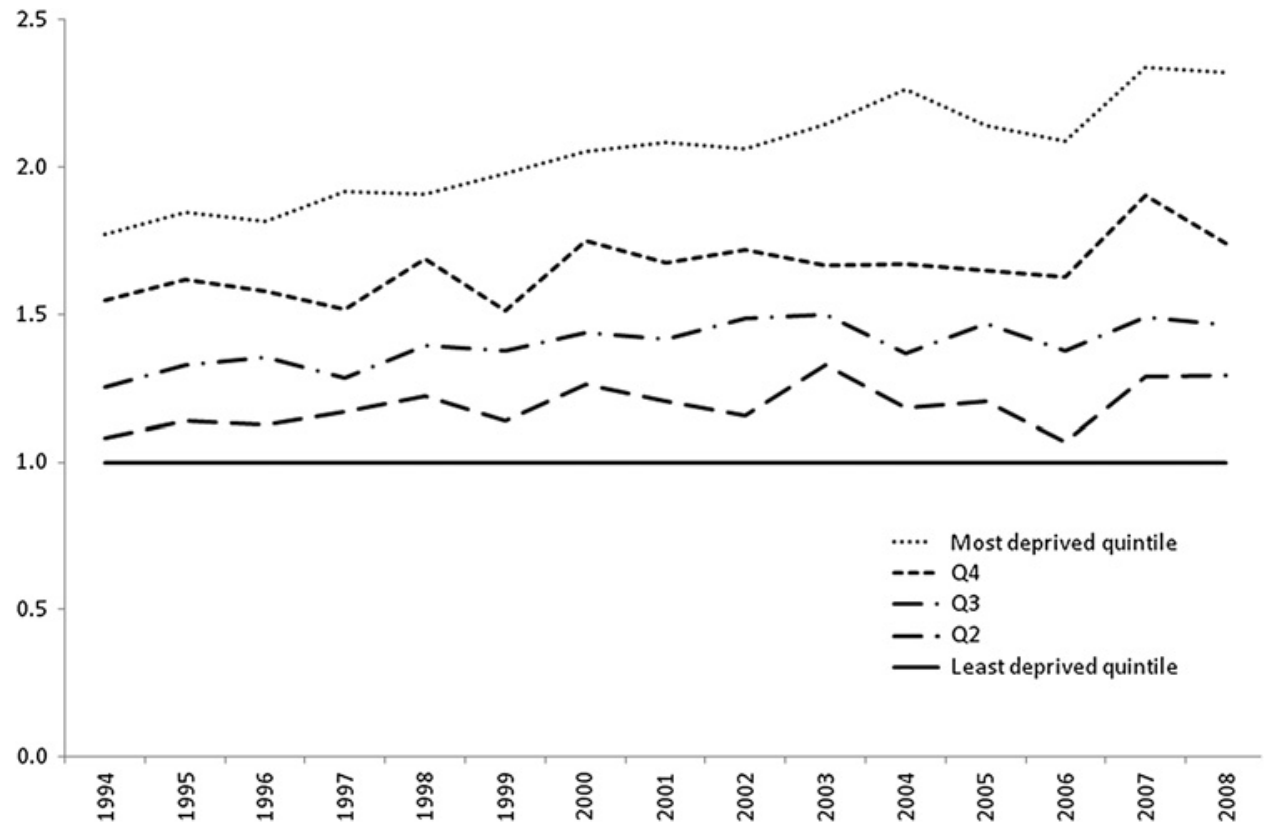

deprivation is not a great predictor of decline in CHD mortality rates: although the general trend shows that decline in CHD mortality between 1994 and 2008 was lower in more deprived areas, there are many examples of deprived local authorities with a large decline over this time period and vice versa (see figure 4).

Well-established behavioural risk factors for CHD such as smoking, poor diet and physical inactivity show an inverse social gradient, as do some medical risk factors for cardiovascular disease (obesity, diabetes and hypertension (in women only)). ${ }^{21}$ Recent work has shown persisting inequalities in risk factors for $\mathrm{CHD}^{22}$-if improvements in prevention and treatment had been experienced equally by populations at each level of deprivation (ie, by equal relative decreases in risk behaviour and increases in risk protection), then we would expect the relative trends to be equal for different deprivation quintiles and the absolute trends in mortality rates for different deprivation quintile to be converging. The implication of this is that, in a situation of falling CHD mortality rates where trends in absolute mortality rates would be expected to be converging, it is important that both absolute and relative mortality rates are presented. One way to use trends in absolute rates for conditions with falling mortality would be to assess where absolute rates for different socioeconomic groups converge-if improvements were being achieved equally across groups, then the rates should converge at the natural floor for the condition, where it is no longer possible to achieve any improvements. For premature
Figure 4 Association between average annual percentage decline in coronary heart disease (CHD) mortality rates between 1994 and 2008 and deprivation, Great Britain-men younger than 75 years.

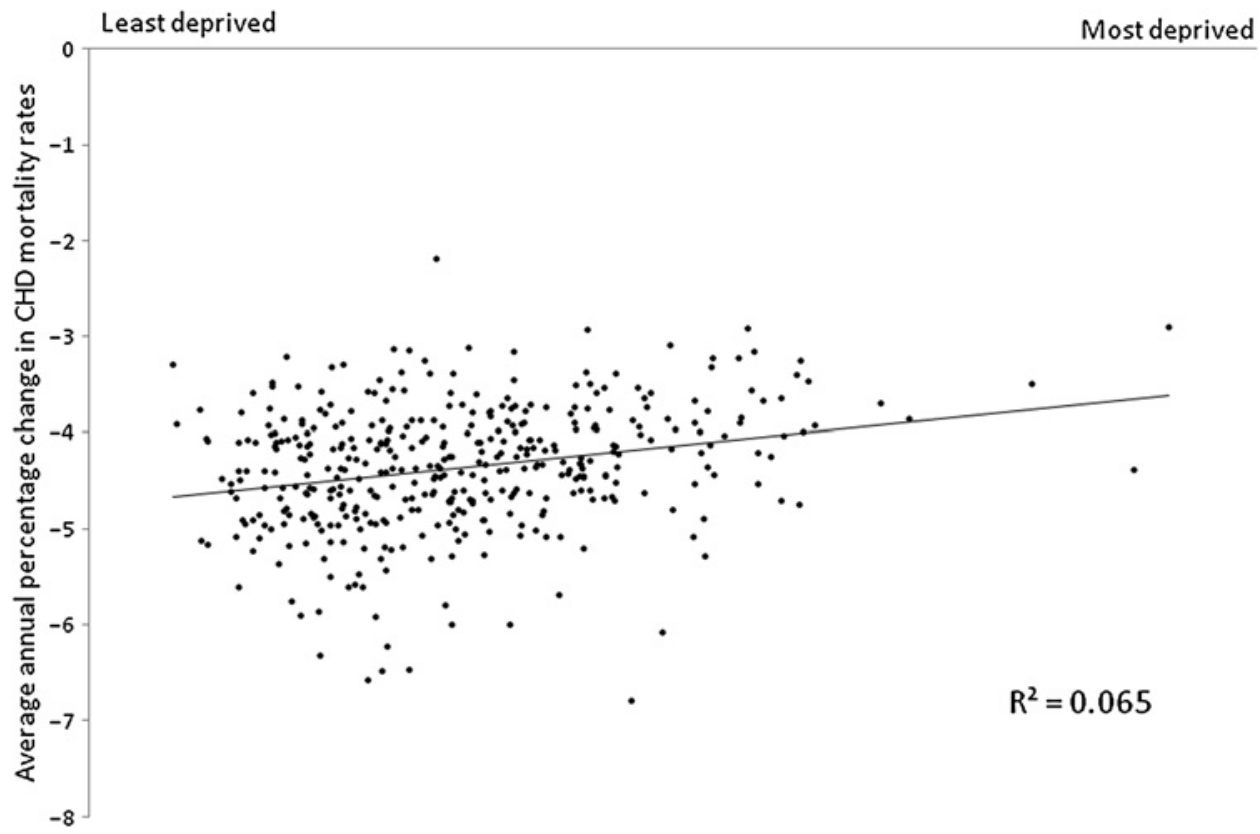


mortality from CHD, this natural floor is likely to be very close to zero. However, our own work has shown that extrapolation of the trends in absolute CHD rates in Great Britain suggest that convergence will not be achieved until 2030 when mortality rates for men younger than 75 years will be -70 per 100000 .

The results presented here concur with the recent report on social inequalities and health 'Fair Society, Healthy Lives', in suggesting that more work needs to be done to reduce social inequalities in health. Suggested mechanisms for reducing inequalities include improving opportunities for active travel, strengthening ill health prevention and ensuring that everyone is able to afford a healthy lifestyle. ${ }^{3}$

The work presented here allows for observation of long-term trends using a consistent small area definition. Often analyses of social inequalities in health are restricted to single countries within the UK, usually because the measure of deprivation that is used is country specific (eg, the Indices of Multiple Deprivation are calculated separately for England, ${ }^{23}$ Scotland $^{24}$ and Wales ${ }^{25}$ ), but this analysis incorporates all local authorities from England, Scotland and Wales. However, a limitation of this study is that deprivation was only measured at a single point in time. The score assigned to each area for 2001, the midpoint of the analysis period, has been assumed to represent the level of deprivation of the area for the entire duration of the study and does not take account for any change in deprivation. This was because the Carstairs index relies on variables that are only available from the national census and are not estimated at intermediary years. It was not possible to calculate equivalent scores using the 1991 census as the units of analysis used for this study (local authorities) did not exist at the time of the 1991 census. Individual local authorities that have seen large changes in social, demographic or economic factors between 1994 and 2008 may have been misclassified by the analyses in this paper. However, the evidence suggests that there have not been substantial misclassification: this was assessed in a separate analysis that used a linear regression analysis of deprivation (assessed using the 2001 Carstairs index) against standardised CHD male and female premature mortality rates for each individual local authority. This analysis was conduced for each year from 1994 to 2008. If there had been substantial misclassification of deprivation by the 2001 Carstairs index, this would result in increasing misclassification bias in years further from 2001 and hence a trend towards larger SEs around the deprivation regression parameter and towards a less well-fitted model. However, this was not observed for either male or female rates (results not shown).

\section{Future work}

This study has only highlighted trends in inequalities over time and has not established the reasons for this trend. Further work is needed to determine socioeco- nomic trends in risk factors, particularly those that have been worsening over time such as obesity and diabetes. ${ }^{26}$ Trend analysis of changing cardiovascular treatments, particular access to surgery, and interventional treatments is worthy of further study. It is also necessary to establish trends in incidence and prevalence of CHD to assess if the gradient mirrors that observed in mortality. Local authority areas that have demonstrated unexpectedly high or low decreases in CHD mortality rates in comparison to other areas of a similar level of deprivation should be examined for potential causal factors.

Contributors DM, PS, MR and PW conceived the study. DM and PS designed the analysis. DM analysed the data and produced the first draft of the manuscript. DM, PS, MR and PW commented on and approved the final manuscript.

Funding MR and PS are supported the by the British Heart Foundation programme grants (PPC/Jul05/5b and PPC/JAN05/6biii).

Competing interests None.

Provenance and peer review Not commissioned; externally peer reviewed.

Data sharing statement There are no additional data available.

\section{REFERENCES}

1. Black D, Morris JN, Smith C, et al. Inequalities in Health: Report of a Research Working Group. London: Department of Health and Social Security, 1980.

2. Acheson D. Independent Inquiry into Inequalities in Health. London: The Stationary Office, 1998.

3. Marmot M, Atkinson T, Bell J, et al. Fair Society, Healthy Lives: The Marmot Review. London: The Marmot Review, 2010.

4. Scarborough $\mathrm{P}$, Bhatnagar $\mathrm{P}$, Wickramasinghe $\mathrm{K}$, et al. Coronary Heart Disease Statistics 2010. London: British Heart Foundation, 2010.

5. Romeri E, Baker A, Griffiths C. Mortality by deprivation and cause of death in England and Wales 1999-2003. Health Stat $Q$ 2006;32:19-34.

6. Department of Health. National Service Framework for Coronary Heart Disease. London: Department of Health, 2000.

7. Kuulasmaa K, Tunstall-Pedoe H, Dobson A, et al. Estimation of contribution of changes in classic risk factors to trends in coronary event rates across the WHO MONICA Project populations. Lancet 2000;355:675-87

8. Sackett DL. Evidence-based medicine and treatment choices. Lancet 1997;349:570.

9. Unal B, Critchley JA, Capewell S. Explaining the decline in coronary heart disease mortality in England and Wales between 1981 and 2000. Circulation 2004;109:1101-7.

10. Marmot MG, McDowall ME. Mortality decline and widening social inequalities. Lancet 1986;328:274-6.

11. Lynch J, Davey Smith G, Harper S, et al. Explaining the social gradient in coronary heart disease: comparing relative and absolute risk approaches. J Epidemiol Community Health 2006;60:436-41.

12. Ramsay SE, Morris RW, Lennon LT, et al. Are social inequalities in mortality in Britain narrowing? Time trends from 1978 to 2005 in a population-based study of older men. J Epidemiol Community Health 2008;62:75-80.

13. Mackenbach JP, Bos V, Andersen $\mathrm{O}$, et al. Widening socioeconomic inequalities in mortality in six Western European countries. Int $J$ Epidiemol 2003;32:830-7.

14. Avendaño $M$, Kunst $A E$, van Lenthe $F$, et al. Trends in socioeconomic disparities in stroke mortality in six European countries between 1981-1985 and 1991-1995. Am J Epidemiol 2005;161:52-61.

15. Department of Health. Tackling Health Inequalities: Status Report on the Programme for Action. London: Department of Health, 2005.

16. Mackenbach JP, Kunst AE. Measuring the magnitude of socioeconomic inequalities in health: an overview of available measures illustrated with two examples from Europe. Europe Soc Sci Med 1997;44:757-71.

17. Blakley $\mathrm{T}$, Tobias $\mathrm{M}$, Atkinson J. Inequalities in mortality during and after restructuring of the New Zealand economy: repeated cohort studies. BMJ 2008;336:371-5.

18. Carstais V, Morris R. Deprivation and mortality: an alternative to social class? Community Med 1989;11:210-19. 
19. Morgan O, Baker A. Measuring deprivation in England and Wales using 2001 Carstairs scores. Health Stat Q 2006;31:28-33.

20. Census Dissemination Unit. Deprivation Scores. http://cdu.mimas.ac. uk/related/deprivation.htm (accessed Jul 2011).

21. Joint Health Surveys Unit. Health Survey for England 2006: Cardiovascular Disease and Risk Factors. Leeds: The Information Centre, 2008.

22. Scholes S, Bajekal M, Love $\mathrm{H}$, et al. Persistent socieconomic inequalities in cardiovascular risk factors in England over 1994-2008: a time-trend analysis of repeated cross-sectional data. BMC Public Health 2012;12:129.
23. Department for Communities and Local Government. The English Indices of Deprivation 2007. London: Department for Communities and Local Government, 2007.

24. Office of the Chief Statistician. Scottish Index of Multiple Deprivation 2009 Technical Report. Edinburgh: The Scottish Government, 2009.

25. Statistics for Wales. Welsh Index of Multiple Deprivation (WIMD) 2008. Cardiff: Welsh Assembly Government, 2008.

26. Scarborough $\mathrm{P}$, Wickramasinghe $\mathrm{K}$, Bhatnagar $\mathrm{P}$, et al. Trends in Coronary Heart Disease 1961-2011. http://www.bhf.org.uk/ publications/view-publication.aspx?ps=1001735 (accessed Feb 2012). 